\title{
Uncomplicated moderate coronary artery dissections after balloon angioplasty: good outcome without stenting
}

M Albertal, G Van Langenhove, E Regar, I P Kay, D Foley, G Sianos, K Kozuma, T Beijsterveldt, S G Carlier, J A Belardi, E Boersma, J E Sousa, B de Bruyne, P W Serruys, on behalf of the DEBATE II Study Group

\begin{abstract}
Objective-To study the relation between moderate coronary dissections, coronary flow velocity reserve (CFVR), and long term outcome.

Methods-523 patients undergoing balloon angioplasty and sequential intracoronary Doppler measurements were examined as part of the DEBATE II trial (Doppler endpoints balloon angioplasty trial Europe). After successful balloon angioplasty, patients were randomised to stenting or no further treatment. Dissections were graded at the core laboratory by two observers and divided into four categories: none, mild (type A-B), moderate (type C), severe (types D to F). Patients with severe dissections $(n=128)$ or without available reference vessel CFVR $(n=139)$ were excluded. The remaining 256 patients were divided into two groups according to the presence (group $\mathrm{A}, \mathrm{n}=45$ ) or absence (group $\mathrm{B}, \mathrm{n}=211$ ) of moderate dissection.

Results-Following balloon angioplasty, there was no difference in CFVR between the two groups. At 12 months follow up, a higher rate of major adverse cardiac events was observed overall in group A than in group B $(10(22 \%) v 23(11 \%), p=0.041)$. However, the risk of major adverse events was similar in the subgroups receiving balloon angioplasty (group A, 6 (19\%) $v$ group B, $16(16 \%)$, NS). Among group A patients, the adverse events risk was greater in those randomised to stenting (odds ratios $6.603 v 1.197, \mathrm{p}=0.046$ ), whereas there was no difference in risk if the group was analysed according to whether the CFVR was $<2.5$ or $\geqslant 2.5$ after balloon angioplasty.

Conclusions-Moderate dissections left untreated result in no increased risk of major adverse cardiac events. Additional stenting does not improve the long term outcome.

(Heart 2001;86:193-198)
\end{abstract}

Hartcentrum

Rotterdam, University

Hospital

Dijkzigt-Thoraxcenter

Bd 408, Dr

Molewaterplein,

40-3015GD Rotterdam,

Netherlands

M Albertal

G Van Langenhove

E Regar

I P Kay

D Foley

G Sianos

K Kozuma

T Beijsterveldt

S G Carlier

E Boersma

P W Serruys

Onze Lieve Vrouwe

Kliniek, Aalst, Belgium

B de Bruyne

Instituto Dante

Pazzanesse de

Cardiologia, São

Paulo, Brazil

J E Sousa

Instituto

Cardiovascular de

Buenos Aires, Buenos

Aires, Argentina

J A Belardi

Correspondence to:

Professor Serruys

serruys@card.azr.nl

Accepted 4 April 2001

Keywords: coronary dissection; intracoronary Doppler; angioplasty

Coronary artery dissection is observed angiographically in up to $50 \%$ of cases after balloon angioplasty. ${ }^{12}$ Although coronary stenting has greatly curbed the need for urgent surgical revascularisation for dissections that impair distal perfusion, it remains to be established whether moderate dissections with unimpaired flow and a good epicardial lumen would benefit from additional stenting. Previous studies have shown that mild to moderate angiographic dissections do not increase the risk of major adverse cardiac events or restenosis rate at a six months follow up after balloon angioplasty. ${ }^{34}$ However, limited data are available on the impact of stenting on the short and long term clinical outcome after the development of moderate dissections.

We investigated the relation between dissection after balloon angioplasty and coronary flow velocity reserve, and the impact of stenting on the subsequent clinical outcome in patients treated by balloon angioplasty or stenting in the DEBATE II trial (Doppler endpoints balloon angioplasty trial Europe).

\section{Methods}

PATIENTS

Patients scheduled to undergo angioplasty because of stable or unstable angina pectoris or documented myocardial ischaemia, caused by a single de novo coronary stenosis less than $25 \mathrm{~mm}$ long and potentially amenable to stent implantation, were eligible for the DEBATE II trial. Those with total coronary occlusions, ostial lesions, bifurcated lesions, lesions in a previously bypassed vessel, lesions in an extremely tortuous vessel, or lesions containing thrombus were excluded from the study, as were patients with previous $\mathrm{Q}$ wave infarction in the myocardial territory supplied by the target vessel, or evolving myocardial infarction in the previous week. The study was carried out according to the principles of the Declaration of Helsinki, and all patients provided written informed consent.

STUDY OBJECTIVES AND DESIGN

The primary objective of the DEBATE II trial was to compare the cost-effectiveness of elective stent implantation (primary stenting) with balloon angioplasty guided by quantitative coronary angiography and Doppler flow velocity measurements. Stent implantation was permitted for bail out situations or whenever an "optimal result" could not be achieved. The secondary objective was to evaluate differences in benefits of additional stenting in patients with and without an optimal result. Thus a double randomisation was required. The first randomisation (1:5) allocated 620 patients to 
either primary stenting ( $n=97$ ) or guided balloon angioplasty $(n=523)$. All patients in the guided balloon angioplasty group who did not require bail out stenting ( $\mathrm{n}=395)$ underwent a second randomisation to additional stenting or termination of the procedure. For the purpose of our analysis, we selected from the latter 395 patients all those $(n=256)$ in whom a reference vessel coronary flow velocity reserve (CFVR) measurement was available, and divided them according to the presence or absence of moderate type $\mathrm{C}$ dissections (fig 1).

\section{GUIDED BALLOON ANGIOPLASTY}

Doppler flow measurements

Target vessel Doppler measurements were performed before and after balloon angioplasty and again following additional stent implantation. It was also a requirement to perform a Doppler assessment of the CFVR of an adjacent angiographically non-diseased reference vessel (<30\% diameter stenosis). A 0.014 inch $(0.36 \mathrm{~mm})$ Doppler guide wire (Cardiometrics FloWire; EndoSonics, Rancho Cordova, California, USA) was advanced distal to the lesion, and velocity recordings were obtained under basal and hyperaemic conditions. Maximum hyperaemia was induced by adenosine, either by an intracoronary bolus injection $(12 \mu \mathrm{g}$ for the right coronary artery and $18 \mu \mathrm{g}$ for the left coronary artery) or by intravenous infusion $(140 \mu \mathrm{g} / \mathrm{kg} / \mathrm{min})$. Absolute CFVR was calculated as the ratio of hyperaemic to baseline time averaged peak velocity. Relative

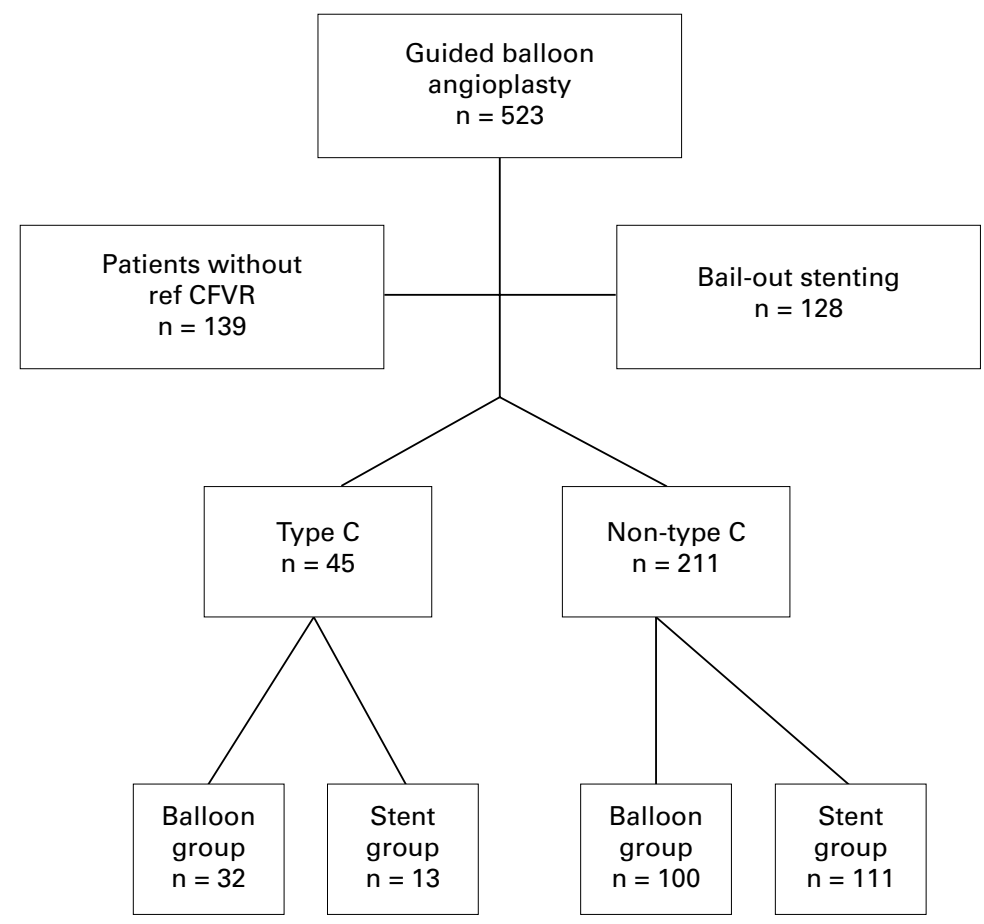

Moderate dissection groups Non-moderate dissection groups

Figure 1 Study population. All patients allocated to the guided balloon angioplasty group of the DEBATE II trial who did not require bail out stenting formed the population for our substudy (395 patients). Of these, 139 had no data of the reference vessel coronary flow velocity reserve available and were therefore excluded from further analysis. The remaining 256 patients underwent a second randomisation to additional stenting or termination of the procedure. We analysed these patients depending on the presence (group A) or absence (group B) of uncomplicated "moderate" dissections.
CFVR was calculated as the ratio of the absolute CFVR to the non-diseased reference vessel CFVR.

\section{Quantitative coronary angiography}

Intracoronary glyceryl trinitrate $0.1-0.3 \mathrm{mg}$ or isosorbide dinitrate $1-3 \mathrm{mg}$ was given to achieve maximum coronary vasodilatation. At least two cineangiograms were performed before the angioplasty or stenting procedure and were repeated in the same projections afterwards. Quantitative angiography was performed using a standardised protocol described previously. ${ }^{56}$

\section{Definition of an "optimal" result}

An "optimal" result (on quantitative angiography and coronary flow reserve determination) was defined as a diameter stenosis of $<35 \%$ and a coronary flow reserve of $>2.5,{ }^{7}$ and was achieved by upsizing the balloon or increasing the inflation pressure, or both, if necessary.

\section{BAIL OUT STENTING}

Bail out stenting was allowed in the following situations: a residual stenosis of more than $50 \%$; dissection of type D, E, or F; persistent myocardial ischaemia along with a dissection type C; a fall in thrombolysis in myocardial infarction (TIMI) flow grade of at least one grade; or TIMI grade 0 or 1 .

SECOND RANDOMISATION

After an optimal result was achieved or when further attempts to improve the result were deemed unsafe by the operator, the final diameter stenosis and coronary flow velocity reserve were assessed. Thereafter, and irrespective of these measurements, the second randomisation was performed.

\section{DISSECTION EVALUATION}

Intimal dissection incidence and grading was determined by an independent core laboratory (Cardialysis BV) classification, ${ }^{1}$ blinded to Doppler flow results and clinical outcome, according to the National Heart, Lung, and Blood Institute (NHLBI) classification:

- type A: small radiolucent area within the vessel;

- type B: no persisting extravasations of contrast;

- type C: persisting contrast medium extravasations;

- type D: spiral filling defect with delayed but complete distal flow;

- type E: persistent filling defect with delayed antegrade flow;

- type F: filling defect with total occlusion. Dissections were clinically divided into "mild" dissections (type A or B), "moderate" dissections (type $\mathrm{C}$ without signs or symptoms of ischaemia), or "severe" dissections (type C with symptoms or signs of ischaemia plus types $\mathrm{D}$ to $\mathrm{F}$ ). The patient population was analysed on the basis of the presence (group A) or absence (group B) of uncomplicated moderate dissections. 
EFFICACY END POINTS

For the DEBATE II study, the efficacy end point was a composite of major adverse cardiac events within 12 months after the procedure and included the following: death from any cause, non-fatal myocardial infarction, and percutaneous or surgical target lesion revascularisation. After hospital discharge, patients were seen at the outpatient clinic at one, six, and 12 months. No follow up angiogram was performed unless clinically indicated.

\section{STATISTICAL ANALYSIS}

Continuous variables are expressed as mean (SD), and differences between groups of patients were studied using the unpaired Student's $t$ test or one way analysis of variance, as appropriate. Categorical variables are presented as percentages, and differences between groups were evaluated using the $\chi^{2}$ test or Fisher's exact test. Multivariate logistic regression analysis was used to study the value of the clinical, angiographic, and Doppler derived data to predict major adverse cardiac events at the 12 months follow up. Odds ratios and $95 \%$ confidence intervals (CI) are presented. The Breslow-Day test was used to assess the homogeneity of odds ratios between subgroups. The

Table 1 Baseline characteristics of the patients according to dissection score following balloon angioplasty

\begin{tabular}{lccl}
\hline \multicolumn{3}{c}{ Dissection } & \\
\cline { 2 - 3 } Characteristic & $\begin{array}{l}\text { Type C (group A) } \\
(n=45)\end{array}$ & $\begin{array}{l}\text { None/type A-B (group B) } \\
(n=211)\end{array}$ & p Value \\
\hline Age (years) (mean (SD)) & $62(11)$ & $57(11)$ & 0.011 \\
Female sex & $33(73 \%)$ & $157(74 \%)$ & NS \\
Diabetes mellitus & $3(7 \%)$ & $23(11 \%)$ & NS \\
Family history & $21(47 \%)$ & $73(35 \%)$ & NS \\
Hypertension & $14(31 \%)$ & $86(41 \%)$ & NS \\
Hypercholesterolaemia & $21(47 \%)$ & $117(55 \%)$ & NS \\
Smoking & $23(51 \%)$ & $145(69 \%)$ & \\
CCS functional class & $3(9 \%)$ & $8(7 \%)$ & \\
$\quad$ I & $19(56 \%)$ & $61(50 \%)$ & \\
II & $11(32 \%)$ & $46(38 \%)$ & NS \\
III & $1(3 \%)$ & $6(5 \%)$ & \\
IV & $11(32 \%)$ & $89(42 \%)$ & \\
\hline
\end{tabular}

Values are $\mathrm{n}(\%)$ unless stated.

CCS, Canadian Cardiovascular Society; type C, moderate dissection; type A-B, very minor dissection.

*Patients with unstable angina were excluded from the analysis of the CCS functional class.

Table 2 Lesion characteristics in the two subgroups

\begin{tabular}{|c|c|c|c|c|}
\hline \multirow[b]{2}{*}{ Characteristic } & & \multicolumn{2}{|l|}{ Dissection } & \multirow[b]{2}{*}{$p$ Value } \\
\hline & & $\begin{array}{l}\text { Type } C(\text { group } A) \\
(n=45)\end{array}$ & $\begin{array}{l}\text { None/type } A-B \\
\text { (group } B)(n=211)\end{array}$ & \\
\hline \multirow[t]{2}{*}{ Eccentricity } & Yes & $31(69 \%)$ & $125(60 \%)$ & \\
\hline & No & $15(31 \%)$ & $85(40 \%)$ & NS \\
\hline \multirow[t]{2}{*}{ Length } & $<10 \mathrm{~mm}$ & $23(51 \%)$ & $95(49 \%)$ & \\
\hline & $\geqslant 10 \mathrm{~mm}$ & $22(49 \%)$ & $92(47 \%)$ & NS \\
\hline \multirow[t]{4}{*}{ Accessibility } & No tortuosity & $43(93 \%)$ & $180(86 \%)$ & \\
\hline & Moderate & $3(6 \%)$ & & \\
\hline & tortuosity & & $28(13 \%)$ & \\
\hline & Excess tortuosity & 0 & $2(1)$ & NS \\
\hline \multirow[t]{3}{*}{ Angulation ${ }^{\star}$} & None & $41(89 \%)$ & $185(88 \%)$ & \\
\hline & Moderate & $5(11 \%)$ & $25(12 \%)$ & \\
\hline & Severe bend point & 0 & 0 & NS \\
\hline \multirow[t]{2}{*}{ Calcification } & Little or none & $39(85 \%)$ & $198(94 \%)$ & \\
\hline & Moderate to heavy & $7(15 \%)$ & $12(6 \%)$ & 0.026 \\
\hline
\end{tabular}

Values are mean $(\%)$

${ }^{\star}$ None, $<45^{\circ}$; moderate, $>45^{\circ}$ to $90^{\circ}$; severe, $>90^{\circ}$. $\log$ rank test was applied to study differences in event-free survival between subgroups at the 12 months follow up. All statistical tests were two tailed, and significance was assumed at $\mathrm{p}<0.05$

\section{Results}

From 523 patients randomised to the guided angioplasty group in the DEBATE II trial, 128 underwent bail out stenting because of severe dissections. All the remaining patients $(n=395)$, irrespective of the presence or absence of a moderate dissection, underwent a second randomisation to additional stenting or to halting the procedure. Of these 395 patients, 139 were excluded from our analysis because no reference CFVR measurements were available. The remaining 256 patients were divided into two groups according the presence (group $A, n=45$ ) or absence (group $B, n=211$ ) of uncomplicated moderate dissections (fig 1).

\section{BASELINE CHARACTERISTICS}

Patients' baseline characteristics are summarised in table 1. Patients in group A were older and had a smaller proportion of smokers than those in group B.

Lesion characteristics are given in table 2. Group A had a greater proportion of calcified lesions than group B. Both groups had similar vessel size (mean (SD): 2.93 (0.43) $\mathrm{mm} v 3.03$ (0.59) $\mathrm{mm}$, group A $v$ group $\mathrm{B}$, respectively (NS)). In group B, 110 of the 211 patients (53\%) had no dissection, whereas 101 (47\%) showed "mild" dissections.

Stent length was similar in both groups $(16.3 \mathrm{~mm} v 15.6 \mathrm{~mm}$ in groups $\mathrm{A}$ and $\mathrm{B}$, respectively; $\mathrm{p}=0.64$ ).

CORONARY DISSECTION SEVERITY AND CORONARY FLOW

For both groups, baseline and hyperaemic averaged peak velocity values before and after the procedure are given in fig 2 . The preinterventional hyperaemic response was slightly impaired in the group A patients randomised to stenting. After balloon angioplasty, both groups showed similar baseline and hyperaemic averaged peak velocity values. In patients randomised to additional stent implantation, no differences in baseline and hyperaemic averaged peak velocities were seen.

Absolute and relative CFVR values are given in table 3. Before and after balloon angioplasty, absolute CFVR was similar in the patient population as a whole. However, in the subgroup randomised to stenting, the absolute CFVR was lower in group A than in group B. As the non-diseased reference vessel CFVR was also significantly lower in group $\mathrm{A}$ than in group B (2.43 (0.71) v 2.91 (0.78), p < 0.001), the resulting relative CFVR after stent implantation was similar in the two groups.

CORONARY DISSECTION SEVERITY AND CLINICAL OUTCOME

Complete follow up data were obtained in all patients. Thirty three cardiac events occurred. There were five deaths (one in group A and four in group B) and six myocardial infarcts 

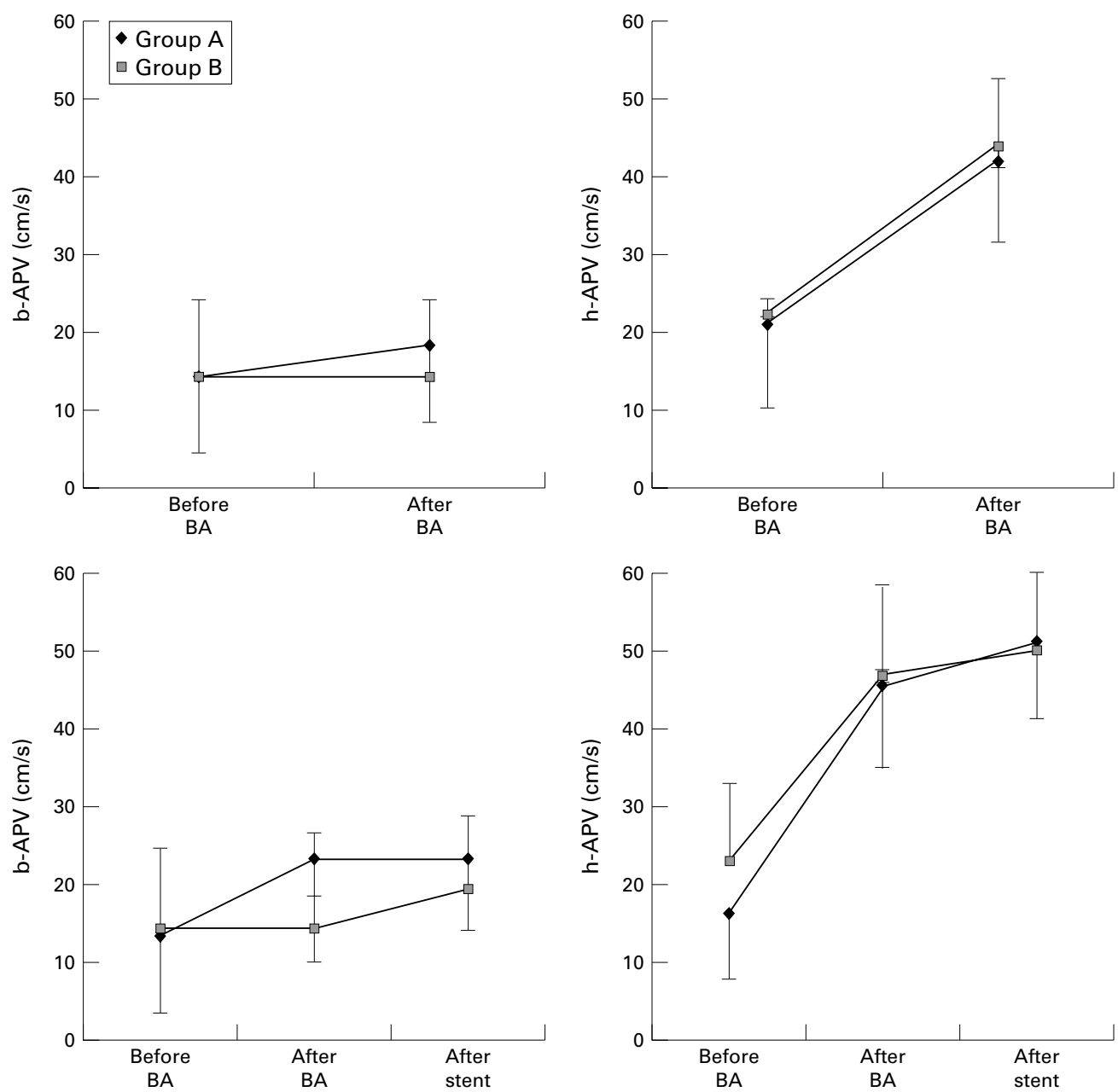

Figure 2 Baseline $(b-A P V)$ and hyperaemic $(h-A P V)$ average peak velocities before and after the procedure in group $A$ and group B. Upper panels show the subgroup randomised to stopping the procedure after balloon angioplasty (BA); lower panels show the subgroup randomised to further stent implantation (stent).

(one in group A and five in group B). At 12 months, the rate of target lesion revascularisation and major adverse cardiac events was higher in group A than in group B (table 4). Event-free survival at 12 months was $78 \%$ in group A $v 89 \%$ in group B ( $\mathrm{p}=0.041)$.

All variables for which univariate analysis yielded a significant difference (age, smoking, degree of lesion calcification) were entered into the multivariate logistic model as potential predictors of major adverse cardiac events,

Table 3 Coronary flow velocity data

\begin{tabular}{lllllll}
\hline & \multicolumn{2}{l}{ Group $A$} & & & Group $B$ \\
\cline { 2 - 3 } & $\begin{array}{l}\text { Stent group } \\
(n=13)\end{array}$ & $\begin{array}{l}\text { Balloon group } \\
(n=32)\end{array}$ & & $\begin{array}{l}\text { Stent group } \\
(n=111)\end{array}$ & $\begin{array}{l}\text { Balloon group } \\
(n=100)\end{array}$ \\
\hline DS before BA (\%) & $76(7)$ & $69(11)$ & & $68(10) \dagger$ & $68(11)$ \\
DS after BA (\%) & $23(8)$ & $23(7)$ & & $22(10)$ & $21(8)$ \\
DS after stenting (\%) & $7(9)$ & - & & $8(8)$ & - \\
CFVR before BA & $1.29(0.32)^{\star}$ & $1.55(0.52)$ & & $1.64(0.61)$ & $1.64(0.60)$ \\
CFVR after BA & $2.04(0.59)^{\star}$ & $2.65(0.95)$ & & $2.50(0.74)$ & $2.50(0.73)$ \\
CFVR after stenting & $2.33(0.87)$ & - & & $2.88(0.30) \dagger$ & - \\
RCFVR before BA & $0.57(0.21)$ & $0.57(0.19)$ & & $0.60(0.25)$ & $0.58(0.21)$ \\
RCFVR after BA & $0.86(0.17)$ & $1.00(0.28)$ & & $0.89(0.27)$ & $0.89(0.27) \dagger$ \\
RCFVR after stenting & $0.97(0.24)$ & - & & $1.02(0.30)$ & - \\
Reference CFVR & $2.43(0.71)^{\star}$ & $2.83(0.81)$ & & $2.91(0.78) \dagger$ & $2.90(0.75)$ \\
\hline
\end{tabular}

Values are mean (SD).

${ }^{\star} \mathrm{p}<0.05 v$ balloon group $\mathrm{A} ; \mathrm{tp}<0.05 v$ same subgroup in group $\mathrm{A}$

$\mathrm{BA}$, balloon angioplasty; CFVR, coronary flow velocity reserve; DS, percentage diameter stenosis; group A, patients with moderate dissections; group B, patients with no or minimal dissection; RCFVR, relative CFVR. along with the presence of moderate dissections. The presence of moderate dissections was the only independent predictor of major adverse cardiac events (odds ratio $2.42 ; 95 \%$ CI, 1.06 to $5.57 ; \mathrm{p}=0.036)$.

IMPACT OF STENTING ON MODERATE DISSECTIONS

Among group A patients, those randomised to stent implantation had a higher rate of major adverse cardiac events than those randomised to stopping the procedure $(31 \%$ v $19 \%)$. The Breslow-Day test for homogeneity of odds ratios between the two patient subgroups was significant, showing a higher risk of major adverse cardiac events at 12 months of follow up in the stent arm (odds ratios $6.603 v 1.197$, $\mathrm{p}=0.046)$. The CFVR (<2.5 $v>2.5)$ before second randomisation did not affect the long term outcome (odds ratios $3.617 \vee 1.410$, $\mathrm{p}=0.287)$.

\section{Discussion}

The main findings of our study are that uncomplicated moderate dissections after balloon angioplasty left untreated had a good long term clinical outcome. In agreement with these results, several angioplasty studies have described a lack of association between the 
Table 4 Clinical outcome at 30 days and 12 months of follow up in the group as a whole and in the two subgroups

\begin{tabular}{|c|c|c|c|c|c|c|c|c|c|}
\hline & \multicolumn{3}{|c|}{ Whole group $(n=256)$} & \multicolumn{3}{|c|}{ Stent group $(n=124)$} & \multicolumn{3}{|c|}{ No further treatment group $(n=132)$} \\
\hline & $\begin{array}{l}\text { Dissection } \\
\text { None/type } \\
\text { A-B (group } \\
B)(n=111)\end{array}$ & $\begin{array}{l}\text { Type } C \\
\text { (group A) } \\
n=45 \text { ) }\end{array}$ & $p$ Value & $\begin{array}{l}\text { Dissection } \\
\text { None/type } \\
\text { A-B (group } \\
B)(n=111)\end{array}$ & $\begin{array}{l}\text { Type C } \\
\text { (group A) } \\
(n=13)\end{array}$ & $p$ Value & $\begin{array}{l}\text { Dissection } \\
\text { None/type } \\
\text { A-B (group } \\
B)(n=100)\end{array}$ & $\begin{array}{l}\text { Type } C \\
\text { (group A) } \\
(n=32)\end{array}$ & $p$ Value \\
\hline MACE (30 days) & $5(5 \%)$ & $3(7 \%)$ & NS & $2(2 \%)$ & $2(15 \%)$ & 0.054 & $3(2 \%)$ & $1(3 \%)$ & NS \\
\hline MACE (12 month) & $23(11 \%)$ & $10(22 \%)$ & 0.041 & $7(6 \%)$ & $4(31 \%)$ & 0.002 & $16(16 \%)$ & $6(19 \%)$ & NS \\
\hline TLR (12 month) & $14(7 \%)$ & $8(17 \%)$ & 0.016 & $3(3 \%)$ & $4(31 \%)$ & $<0.001$ & $11(11 \%)$ & $4(13 \%)$ & NS \\
\hline
\end{tabular}

Values are $\mathrm{n}(\%)$.

MACE, major adverse cardiac events; TLR, target lesion revascularisation.

presence of a moderate dissection and the long term clinical outcome. ${ }^{8-10}$ Previous three dimensional intracoronary ultrasound data from our group have shown that the presence of intimal dissection is associated with a greater total vessel volume at long term follow up, probably owing to favourable remodelling. ${ }^{11}$ It is conceivable that the development of a more deeply seated injury reduces vessel wall strength, thereby predisposing to favourable remodelling.

Overall, the patients with moderate dissections had a worse outcome than those with no or minimal dissections. This probably reflects the findings in the stented subgroup, which had a higher risk of major adverse cardiac events than the group with moderate dissections but without additional stenting. Although stents were placed according to the DEBATE II protocol and not to the operator's preference, the small sample size $(n=13)$ prevents us from drawing any firm conclusions. While coronary stenting after the development of moderate dissections has proved to reduce the acute complication rate, there is no established long term clinical benefit of additional stenting in patients with uncomplicated moderate dissection (TIMI 3 flow and absence of signs or symptoms of angina). Recent reports have shown that coronary stent implantation causes more severe injury and a greater inflammatory response, as well as worse endothelial dysfunction, than plain balloon angioplasty. ${ }^{12-15}$ It is conceivable that the combination of a deep arterial injury associated with a moderate dissection and the implantation of a metallic body may cause a synergistic proliferative response. ${ }^{16}$ In patients with moderate dissections, preventing favourable remodelling might offset the beneficial stent scaffolding effect. The latter could be particularly important as these patients are expected to develop an enhanced neointimal response. ${ }^{16}{ }^{17}$

Our group has previously reported a temporary reduction in absolute coronary flow reserve in patients who developed uncomplicated moderate dissections. ${ }^{18}$ This reflected a transient increase in the baseline velocity. Therefore the reduced coronary flow reserve values did not translate into a greater residual stenosis and obstruction of coronary blood flow. In the present study, we used the relative CFVR - a more reliable index of persistent conduit obstruction than the absolute CFVR $^{19}$ - and found similar values between the two groups. The latter results indicate that without signs or symptoms of ischaemia and the presence of TIMI 3 flow, no significant obstruction to coronary blood flow should be expected in patients experiencing mild to moderate dissections.

Although the use of long or multiple stents has recently been reported to be associated with a greater restenosis risk, ${ }^{20-22}$ in our study similar lengths and numbers of stents per patient were used in the two groups, so this is unlikely to be a confounding factor.

\section{LIMITATIONS}

The limited number of patients with moderate dissections prevents us from drawing definitive conclusions. However, this is the largest prospective study investigating a selected population of patients who developed uncomplicated moderate dissections and underwent randomisation to additional stenting or no further treatment, and in whom post-procedural Doppler flow data and one year follow up data were available.

CONCLUSIONS

Moderate dissections left unstented do not have an adverse clinical outcome. Additional stenting does not appear to be of benefit.

1 Dorros G, Cowley MJ, Simpson J, et al. Percutaneous transluminal coronary angioplasty: report of complications from the National Heart, Lung, and Blood Institute PTCA registry. Circulation 1983;67:723-30.

2 Guiteras Val P, Bourassa MG, David PR, et al. Restenosis Guiteras Val P, Bourassa MG, David PR, et al. Restenosis after successful percutaneous transluminal coronary Cardiol 1987;60:50-55B

3 Hermans WR, Rensing BJ, Foley DP, et al. Therapeutic dissection after successful coronary balloon angioplasty: no influence on restenosis or on clinical outcome in 693 patients. The MERCATOR study group (multicenter European research trial with cilazapril after angioplasty to prevent transluminal coronary obstruction and restenosis). $\mathcal{F}$ Am Coll Cardiol 1992;20:767-80.

4 Rupprecht HJ, Brennecke R, Bernhard G, et al. Analysis of risk factors for restenosis after PTCA. Cathet Cardiovasc Diagn 1990;19:151-9.

5 Di Mario C, Haase J, den Boer A, et al. Edge detection versus densitometry in the quantitative assessment of stenosis phantoms: an in vivo comparison in porcine coronary arteries. Am Heart f 1992;124:1181-9.

6 Haase J, Di Mario C, Slager CJ, et al. In-vivo validation of on-line and off-line geometric coronary measurements using insertion of stenosis phantoms in porcine coronary arteries. Cathet Cardiovasc Diagn 1992;27:16-27.

7 Serruys PW, di Mario C, Piek J, et al. Prognostic value of Serruys PW, di Mario C, Piek J, et al. Prognostic value of
intracoronary flow velocity and diameter stenosis in assessintracoronary flow velocity and diameter stenosis in assessangioplasty: the DEBATE study (Doppler endpoints balloon angioplasty trial Europe). Circulation 1997;96: 3369-77.

8 Huber MS, Mooney JF, Madison J, et al. Use of a morphologic classification to predict clinical outcome after dissection from coronary angioplasty. Am $\mathcal{F}$ Cardiol 1991;68:46771.

9 Sharma SK, Israel DH, Kamean JL, et al. Clinical, angiographic, and procedural determinants of major and minor coronary dissection during angioplasty. Am Heart $\mathcal{f}$ 1993;126:39-47.

10 Cappelletti A, Rosano G, Mailhac A, et al. Short- and longterm evolution of unstented nonocclusive coronary dissection after coronary angioplasty. 7 Am Coll Cardiol 1999;34: tion after $1484-8$.

11 Costa MA, Kozuma K, Gaster AL, et al. Three dimensional intravascular ultrasonic assessment of the local mechanism of restenosis after balloon angioplasty. Heart 2001;85:73-9. 
12 Caramori LV, Seidelin PH, Newton GE, et al. Long-term endothelial dysfunction after coronary artery stenting. $\mathscr{f}$ Am Coll Cardiol 1999;34:1675-9.

13 Hanke HKJ, Hassenstein S. Prolonged proliferative response of smooth muscle cells after experimental intravascular stenting. Eur Heart F 1995;6:785-93.

14 Hoffmann R MG, Dussaillant GR. Chronic arterial response to stent implantation: a serial intravascular ultrasound analysis of Palmaz-Schatz stents in native coronary arteries. F Am Coll Cardiol 1996;28:1134-9.

15 Hofma SHWD, van Beusekom HM, Verdow PD, et al. Increasing arterial wall injury after long-term implantation of two types of stent in a porcine coronary model. Eur Heart f 1998;19:601-9.

16 Farb A, Sangiorgi G, Carter AJ, et al. Pathology of acute and chronic coronary stenting in humans. Circulation 1999;99: 44-52.

17 Schwartz RS, Huber KC, Murphy JG, et al. Restenosis and the proportional neointimal response to coronary artery injury: results in a porcine model [see comments]. 7 $\mathrm{Am}$ Coll Cardiol 1992;19:267-74.
18 Albertal M, Van Langenhove G, Kay IP, et al. Angiographic and clinical outcome of mild to moderate nonocclusive unstented coronary artery dissection and the influence on coronary flow velocity reserve. The Debate I study group. Am 7 Cardiol 2000;86:375-8.

19 Baumgart D, Haude M, Goerge G, et al. Improved assessment of coronary stenosis severity using the relative flow velocity reserve. Circulation 1998;98:40-6.

20 Haude M, Erbel R, Straub U, et al. Short and long term results after intracoronary stenting in human coronary
arteries: monocentre experience with the balloonarteries: monocentre experience with the balloon-
expandable Palmaz-Schatz stent. Br Heart f 1991;66:33745.

21 Kasaoka S, Tobis JM, Akiyama T, et al. Angiographic and intravascular ultrasound predictors of in-stent restenosis. $\mathcal{F}$ Am Coll Cardiol 1998;32:1630-5.

22 Ellis SG, Savage M, Fischman D, et al. Restenosis after placement of Palmaz-Schatz stents in native coronary arteries. Initial results of a multicenter experience. Circulation $1992 ; 86: 1836-44$.

\section{IMAGES IN CARDIOLOGY}

\section{Obliteration of a coronary artery aneurysm with a covered coronary stent}

A 71 year old man with a history of limiting stable exertional angina who had required admission for unstable angina on two occasions in the preceding year underwent elective coronary angiography. Risk factors included hypertension, non-insulin dependent diabetes, hypercholesterolaemia, and previous smoking. Angiography showed single vessel disease of the left anterior descending artery (LAD) (top: right anterior oblique $30^{\circ}$ caudal $10^{\circ}$ ). Just distal to the first diagonal there was a discrete coronary aneurysm with a severe stenosis proximally. After pre-inflation with a $2.5 \mathrm{~mm}$ balloon a $16 \times 3.5 \mathrm{~mm}$ JoMed Jostent coronary stent graft was deployed at $18 \mathrm{~atm}$, achieving excellent flow in the LAD and aneurysm obliteration (bottom: right anterior oblique $45^{\circ}$ caudal $10^{\circ}$ ). The patient was discharged on a one month course of clopidogrel and remains asymptomatic at follow up.

The Jostent coronary stent graft is a polytetrafluoethylene (PTFE) stent sandwich ideally suited for treatment of coronary aneurysms, perforations, and fistulae.

N R A CLARKE

A P BANNING

adrian.banning@orh.anglox.nhs.uk
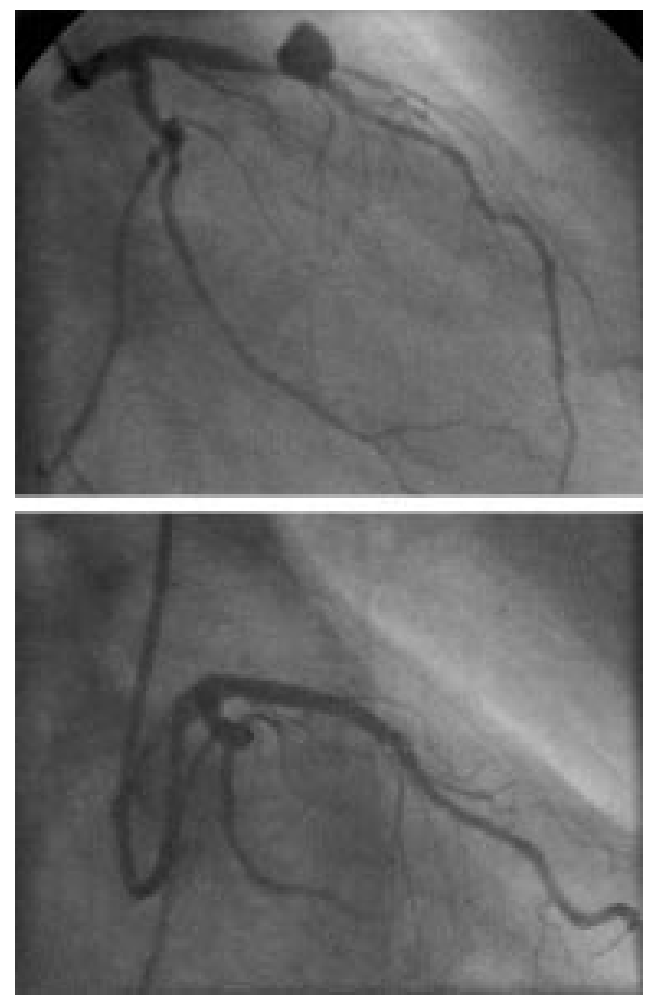